\title{
Маркирование кавычками в сибирской публицистике XIX в. как средство актуализации языковых процессов и источник толковой и исторической лексикографии
}

Ключевые слова: кавычки, лексикография, семантика, сибирские источники. Key words: quotation marks, lexicography, semantics, Siberian sources.

\begin{abstract}
The article shows the role of quotation marks as a means of actualizing new vocabulary and marking semantic processes and stylistic characteristics of words in the works of Siberian publicists. The material of the essays can serve as an empirical base for the $19^{\text {th }}$-century differential dictionary and the Great Academic Dictionary of Russian language.
\end{abstract}

\section{Введение}

Среди пунктуационных средств русского языка кавычки занимают особое место. Как известно, в современном русском языке кавычки употребляются как знак, отделяющий прямую речь от слов автора, если прямая речь «идёт в строку»; кавычками выделяется и так называемая внутренняя речь, «невысказанные мысли» [Rozental' 1994: 303, 304]. Кроме того, кавычки используются для выделения приложений - названий литературных произведений, газет, журналов, музыкальных произведений; судов, гостиниц, организаций, фирм; орденов, медалей, марок машин и др. [Rozental' 1994: 330-332]. В XIX в. Я.К. Грот в первом своде русских правил в списке знаков 
препинания указывает точку, точку с запятой, двоеточие, запятую, а о кавычках говорит лишь в примечаниях к употреблению двоеточия: «Передъ началомъ и при концъ приводимыхъ авторомъ чужихъ словъ, заглавій и т.п. обыкновенно ставятся кавычки, или вносные знаки « ». При цитатахъ нужны кавычки только тогда, когда выписка дълается слово въ слово» [Grot 1895: 104]. Однако в современном русском языке кавычки могут маркировать слова непривычные, малоупотребительные, на которые автор хочет обратить внимание, слова, употребленные в особом, необычном значении, малоупотребительные термины, устарелые или, наоборот, новые слова; прецедентные слова и выражения, слова, употребленные в условном значении, и др. случаи лексико-семантической и стилистической маркировки лексики [Rozental' 1994: 327-329]. Важно, что Д.Я. Розенталь указывает на то, что к концу XX в. «замечается убывание случаев употребления кавычек в подобных выражениях по мере того, как они становятся обиходными» [Rozental' 1994: 329]. В то же время другие исследователи обращают внимание на положительную роль кавычек в оценочно-стилистической функции [Švarckopf 1967: 60-64].

В XIX в. в своде правил лексико-семантическая и стилистическая функция кавычек не фиксируется, но в текстах журнальной периодики, как показали наши наблюдения, кавычки представлены не только при передаче прямой речи.

Цель исследования - выявить функции кавычек в произведениях писателей-сибиряков и их роль в актуализации лексико-семантических процессов в литературном языке XIX в. и в формировании стилистических норм русского литературного языка.

Объектом настоящего исследования являются лексические единицы, маркированные кавычками в сибирских источниках.

Материал был извлечён из четырёх очерков сибирских публицистов: «Крестьяне-старожилы Нарымскаго края» (авт. Николай Петрович Григоровский, 1870 г.), «Путь по хльбороднымъ мъстамъ. Отъ Барнаула до Егорьевска» (авт. Александр Шерстобитов, 1899 г.); «Къ описанію городовъ и селеній. Святки у тобольскихъ крестьянъ» (1899 г.), «Къ описанію городовъ и селеній II. Крестьянская свадьба въ Туринскомъ уъздъ, Тобольской губернии» (1899 г., два последних очерка подписаны именем Марк Квитка, полагаем, это псевдоним) [Grigorovskij 1870; Kvitka 1899a, 1899b; Šerstobitov 1899].

Литературное и научно-публицистическое наследие писателей-сибиряков, ученыХ-путешественников второй половины XIX - начала XX вв. Н.П. Григоровского, Г.Е. Катанаева, Г.Н. Потанина, И.Я. Словцова, А. Шерстобитова, Н.М. Ядринцева и др. вызывает интерес у историков, этнографов, но недостаточно изучено лингвистами. Выбор материала исследования находится в полном соответствии с реализацией принципов, которые нацеливают на формирование эмпирической базы нового исторического 
дифференциального «Словаря русского языка XIX века», прежде всего, это «принцип жанрово-стилистического многообразия» привлекаемых источников, во-вторых, «принцип объективности», предполагающий «свободный, не зависящий от идеологических, эстетических и пр. установок и оценок, выбор источников» [Proekt 2002: 39]. Обращение же к журнальной публицистике соотносится с установками авторов Словаря XIX в., обращающих особое внимание на «мощное и усиливающиеся» влияние прессы XIX в. «на широкие круги читателей» [Proekt 2002: 41; Filin 1981]. Сибирские материалы, кроме того, могут расширить не только эмпирическую базу, но и семантическую зону словарной статьи третьего издания большого толкового словаря, над которым работают лексикографы Института лингвистических исследований РАН (г. Санкт-Петербург). Полагаем, что эти соображения определяют актуальность предпринятого исследования.

\section{Анализ материала}

Лексическая система литературного языка во второй половине XIX в. активно притягивает к себе элементы городского просторечия, народной и областной речи. Именно в журналах была представлена «литература всех жанров, стилей, направлений, художественных уровней» [Proekt 2002: 41], в том числе и интересный, типичный для XIX в. жанр, - «описание чужих земель» [Proekt 2002: 44]. Очерки, отобранные нами для анализа, являются источником научно-популярных знаний, они характеризуют социально-экономическое состояние, географическое положение края, подробно описывают обряды и обычаи сибиряков. Но при этом эти тексты, думается, ценны и как произведения, отличающиеся определенными художественными достоинствами.

Как отмечается в Проекте, «одной из характерных для XIX в. тенденций было пополнение словарного состава русского литературного языка за счет „вчерашних” диалектизмов» [Proekt 2002: 31]. В рассматриваемых очерках диалектные лексемы составляют более половины (81\%) от общего числа единиц (отобрано 119 лексических единиц, демонстрирующих основные тенденции развития лексики XIX в.).

Писатели-сибиряки, характеризуя обычаи и традиции местных крестьян, постоянно знакомят читателей с новыми реалиями и, соответственно, с новыми словами. Такие слова присутствуют не только в описаниях пространств Сибири и обычаев, но и в речах коренных жителей, записанных авторами очерков. Как вводят в обиход локальную лексику публицисты-сибиряки? Местная лексика могла толковаться ими в самом тексте с помощью конструкций: носящих название, называется, называют, здесь называется, то 
есть и т.п.; или объяснение могло быть дано в виде сноски внизу страницы. Нередко, однако, диалектная лексика маркируется в текстах графически при помощи кавычек.

(1) Первую группу слов, выделенных кавычками, составляют номинации пространств Сибири: И теперь вст дъвственные, некультивированные углы огромных сибирских пространствъ, носящих название то «тайги», то «черни» [...] (тайга 'полоса диких труднопроходимых хвойных лесов на севере Европы, Азии и Америки’ [MAS 1999: 331; Ožegov 1984: 683]; чернь [Harlamova 2019: 268-269]) [Šerstobitov 1899: 28];

У возвышеннаго берега ръчки Чесноковки, которая весною сливается с Обью, у «елбана», как здъсь называютъ такой высокій, обрывистый берегъ, всегда стоить иелая флотилія большихъ и малых лодок (е 'лбан в современном языке - диалектное слово, широко распространено на территории Сибири [SRNG-8: 338]) [Šerstobitov 1899: 19].

Следует отметить, что графическое выделение часто сочетается с названными уже вербальными средствами.

(2) Вторую группу составляют названия строений, жилищ, их частей и предметов интерьера: Въ первой отъ съней комнатғ, такъ называемой «избъъ, нъьсколько мужиковъ и бабъ, ведущихъ между собою оживленный разговоръ. В смежной комнатп, горницъ, 8-10 дъвушекъ (изба 'жилое помещение в крестьянском доме; крестьянский дом; кухня’) [Kvitka 1899a: 46];

Жаль всей этой «горницыл» съ ея полатями и печью (горница 'чистая половина крестьянского дома') [Šerstobitov 1899: 27];

Посль крещенія, для младениа, гдг нибудь в избг, на очипг, въсять люльку, которую здгсь называютъ «зыбкою», и кладутъ в нее будущаго крестьянина (зыбка 'колыбель') [Grigorovskij 1870: 2];

Желая узнать, будеть ли мужь пахарь или кто-нибудь другой, гадающая подходит къ амбару или къ завознғи, крестообразно захвативши вытянутыми въ противоположные стороны руками [...] считаеть ихъ снизу или свъьрху, приговаривая: «сустьк» - «мъъио» (сусек 'место в амбаре, куда ссыпается зерно') [Kvitka 1899a: 50].

Ещё одно диалектное слово маркировано кавычками в тексте М. Квитки, связанное со второй тематической группой - это отглагольное существительное обихаживание 'уборка дома, избы' (от глагола обихаживать 'обеспечивать уходом, заботой' [SRNG-31: 123]).

Итак, как показывает проведенный анализ, слова из двух групп имеют разный статус в современном языке, одни используются в литературном языке даже без помет (тайга, изба), другие (чернь, елбан, зыбка, сусек, обихаживание) - не сохранились в составе литературного языка и функционируют только в народно-разговорной речи и/или известны в литературном языке 
как устаревшие (горница) и стилистически маркированные (народно-поэтическое: горницза).

(3) Большую группу составляют обозначения лиц:

Изъ города въ городъ чрезъ Чесноковку [...] пдутт [...] разнаго рода чиновники - акиизные, полицейскіе, кабинетскіе и проч., «воздушники» и «кумысники» на Алтай, на чистый воздухъ и минеральные источники (воздушники и кумыссники 'человек, приехавший на Алтай для отдыха и поправки здоровья') [Šerstobitov 1899: 16];

Въ Баранульскомъ и Бійском уґздахъ не говорять - «женщина» или какъ в другихъ мъстахъ «баба», «бабы», а- «женска», «женски». И приводятся примеры: «Ну, женски, скорге! - Эй, женска, чья ты будешь?» (женска 'женщина') [Šerstobitov 1899: 19].

Лексемы воздушник и кумысник позволяют проследить и подтвердить активность словообразовательной модели - образование лица, деятеля с помощью суффикса -ник. Кумысник образовано от диалектной лексемы кумыс 'кисломолочный напиток из кобыльего молока у скотоводческих народов Азии' [Černyh 2002: 454]. По аналогии возникло и второе слово, основой для которого послужила общеупотребительная лексема воздух. Нам не удалось обнаружить эти слова в словарях XIX в., их можно отнести к локальной окказиональной лексике того периода. Думается, эти слова созданы для более точного описания реалии сибирского быта, на базе описательных оборотов и с использованием ставшей продуктивной именно в XIX в. модели [Proekt 2002: 36].

В очерке Н.П. Григоровского графически выделены имена, обозначающие лиц по роду деятельности:

Передъ сумерками изъ молодыхъ ребятъ выбирается «загоншикъ», который долженъ знать, кого нужно позвать на вечеринку (загонщик 'молодой человек, приглашающий гостей на вечеринку') [Grigorovskij 1870: 17];

Иногда силой залучать ее когда нибудь въ избу покачать въ зыюкгь своего крикуна-братишку, за что ее и называют «нянюшкой» (нянюшка 'старшая дочь, ухаживающая за младшими детьми в семье') [Grigorovskij 1870: 16] (ср. в русских говорах бытует исходная форма, являющаяся производящей в словообразовательной модели, няня 'старшая сестра', которая ухаживает за младшими в семье, территория распространения Орловская, Олонецкая, Псковская, Омская, Новосибирская, Иркутская, Кемеровская, Нижегородская, Куйбышевская и др. [SRNG-21: 333-334]);

Но стряпуха, которая здтьсь называется «стряпчею» никогда не позаботится, чтобы не перепргло мясо, или не вспльль чугунъ (стряпчая 'кухарка' [SRNG-42: 386]) [Grigorovskij 1870: 19].

При описании празднования святок М. Квитка в кавычках вводит в текст название мифического существа: 
Подойдя къ нимъ, дъваха становится спиною къ окну овина и ждетъ, погладить ли ее по спинг мифический «овинный» (овинный 'домовой, который живет или его можно увидеть в овине', овин 'строение для сушки хлеба в снопах') [Kvitka 1899a: 50] (аналогичная семантика до сих пор сохраняется в говорах [SRNG-22: 299]).

Среди номинаций отмечены оценочные названия детей с прозрачной внутренней формой:

Чтобы не было очень тъосно таниуюшимъ, этихъ маленькихъ «глазуновъ» отправляють на полати (глазун 'ребёнок, который еще слишком мал, чтоб участвовать в вечерках и приходит туда «поглазеть», т.е. посмотреть') [Grigorovskij 1870: 18];

До того времени, когда ребенокъ будеть окрещенъ, на него не надъвають рубашки, почитая это неприличнымъ, да и называютъ его до крещеенія «татариномъ» (см. о развитии семантики лексемы татарин [Harlamova 2019: 271]) [Grigorovskij 1870: 2].

Можно выделить и группу (4) лексики, манифестирующую традиции и обряды:

Если дъвушка "работяща», и къ тому же единственная въ семьг, то родители итьнять ее очень дорого и никогда, даже за большой «кольмъ», рано не выдадуть ее замужь (кольмм 'цена за невесту') [Grigorovskij 1870: 13];

Съ этого времени у дъввочки бывають и «подруги», которыя приходять к ней съ пряхами, или она отправляется к нимъ на такъ называемыя «nосидънки» (посиденки 'послеобеденное собрание молодых крестьянок и хозяек для работы и развлечения’) [Grigorovskij 1870: 16].

В первом контексте (группа 4) маркировано диалектное слово работящяа, дающее характеристику человека (5), причем по происхождению это стяженная форма действительного причастия настоящего времени. Подобные причастия в говорах до сих пор выступают в атрибутивной функции как прилагательное и с оценочной семантикой (оформляют превосходную степень прилагательных) [Russkaâ dialektologiâ 1972: 202].

В оценочной функции представлено и диалектное прилагательное с синкретичной семантикой могутный (сибирское) 'богатый, зажиточный, сильный, здоровый, крепкий’ в очерке А. Шерстобитова [Dal' 1989: 337; SGSrP-2: 182]:

И только еще болье «цуґпкіе и могутные» крестьяне, мало нуждаясь в деньгахъ, воздерживаются отъ продажи скопленнаго хльба [Šerstobitov 1899: 20-21].

Выделены кавычками и слова тематических групп (6) пища и (7) одежда: 
Колются поросята, телята, рғжутся гуси, куры, варится пиво, квасъ, стряпается хлъбъ, «прикусочка» (прикусочки 'лакомство, выпечка' [SRNG-31: 458]) [Grigorovskij 1870: 19];

Нгъсколько большихъ лавокъ съ «красным» и галантерейнымъ товаромъ, оборудованныхъ по образиу городскихъ магазиновъ, большіе, построенные на городской ладъ дома, «спинжаки» на улищахъ, на площадяхъ, и у дворовыхъ вороть, какіе то слоняющіеся безъ дюла люди, судя по костюму, чуждые земледгъльческому, крестьянскому труду (спинжак 'пиджак' [SRNG-40: 143]) [Grigorovskij 1870: 19].

Итак, лексемы, маркированные кавычками, из групп (3-6) представляют собой слова, ограниченного употребления, бытующие в XIX в. и в настоящее время в основном в народных говорах. Одни из них представляют собой диалектный вариант литературного слова (словообразовательный вариант спинжак), другие - показывают развитие метонимических значений и закрепление новой семантики в маркированной в тексте лексеме (прикусочки 'лакомство, выпечка', ср.: прикусочки 'прикусывающего и прикусившего' от прикусывать 'процесс поглощения пищи' [Sl. cerk.-sl. 1947: 483]), а в словарях современного языка у них отмечается ареал распространения (те же прикусочки - исключительно территория Сибири [SRNG-31: 458]) или наблюдается специализация в семантике (загонщик 'тот, кто загоняет, выгоняет зверя на охотников при облаве' [Ožegov 1984: 174]). Большая часть графически выделенных слов до сих пор стилистически и функционально маркированы: употребляются в говорах (могутный, глазун) или в разговорной речи (кумысник), в литературном же языке имеют пометы нар.-разг. (народно-разговорное), нар.-поэт. (народно-поэтическое - горница) и/или устар. (устаревшее - прикусочки в форме прикуски).

Некоторые «закавыченные» слова в XX в. оказались в словарях русского языка, но функционируют с иным значением (прикусочки 'хлеб, ватрушка, пирог, печенье, подаваемые к чаю' [SRNG-31: 266], а в литературном языке выступает как наречие вприкуску [Ožegov 1984: 88], имеющее значение 'пить чай, прикусывая сахар', т.е. сохраняющее основной и древний смысл 'лакомство'). Общеупотребительная лексика, известная и сейчас в литературном языке, в анализируемых текстах демонстрирует сужение семантики: татарин (cp. татарин в [Ožegov 1984: 686]); няня (в тексте нянюшка- производное от няня, cp. [Ožegov 1984: 361]); в литературном языке есть одно из актуальных в XIX в. значений у овинный (cp. [Ožegov 1984: 378]); а слово колым представлено в современном литературном языке в другом написании - калым, в семантике же лексикографы ограничивают территорию его функционирования - 'у некоторых народностей Востока, сохранивших обычаи родового быта: выкуп, вносимый женихом родителям своей невесты' и дают еще одно значение [Ožegov 1984: 226]. 


\section{Выводы}

В XIX в. усиливается процесс демократизации литературного языка, происходит расширение объёма понятия «литературности», что демонстрирует сибирская публицистика [Filin 1981: 183-187 и др.]. Авторы анализируемых очерков, не являясь профессиональными лингвистами, собирателями и исследователями говоров, с особой тщательностью фиксировали диалектные лексемы, выделяли их графически, толкуя либо в самом тексте, либо в сносках в конце страницы.

Сравнение лексики, маркированной кавычками в анализируемых очерках, с данными различных словарей показывает тенденции развития лексикосемантической системы языка (семантические сдвиги и новации; освоение иноязычных слов, развитие словообразовательных моделей, стилистической окраски и т.п.). В XIX в. происходит расширение границ употребления лексических единиц - характерная для этого периода тенденция, которую подтверждают наши наблюдения: ранее ограниченные сферой применения слова становятся общеупотребительными (тайга, изба, калымм). Маркированная кавычками лексика позволяет увидеть динамические тенденции в русском языке, связанные с формированием и закреплением норм. За два столетия, как показал анализ, часть лексики сменила свой статус: ограниченное употребление (диалектное) > общеупотребительное $>$ устаревшее и/или народно-поэтическое, областное; например, слово горница (диалектное) > литературный язык > литературное устаревшее или народно-поэтическое [Ušakov 1935: 600; Ožegov 1984: 120]. Другой пример - слово кумысник: локальное окказиональное (в тексте) > разговорное (помета новое разговорное [Ušakov 1935: 1548]); лексема калым, в тексте колым: местное > литературное (без стилистических помет, но с указанием территории распространения в дефиниции [Ožegov 1984: 226; TÈS 2006: 724]). Диалектные слова, выделенные авторами графически, толковались и вводились в обиход, знакомя европейцев с особенностями сибирских пространств. Именно средоточением процессов, протекавших в языке в это время, стал публицистический стиль. Таким образом, не отмеченная Я.К. Гротом функция кавычек, маркирующая новые для читателей слова и их оценочно-стилистическую характеристику, продуктивно используется сибирскими публицистами.

На наш взгляд, региональные публицистические тексты последней трети XIX в., изданные в Сибири, являются ценным источником дифференциального исторического Словаря XIX в. и могут быть привлечены к работе над Большим академическим словарём в качестве верифицирующего источника, поскольку лексикографы ставят своей целью зафиксировать изменения в лексико-семантической системе языка и сложение стилистических норм. 


\section{Источники}

MAS 1999 - Evgen'eva A.P. (ed.), 1999, Slovar' russkogo âzyka v 4 tomah (Malyj akademičeskij slovar'), vol. 4, Moskva: Russkij âzyk.

Proekt 2002 - Slovar' russkogo âzyka XIX veka: Proekt, 2002, Sankt-Peterburg: Nauka. SGSrP-2 - Sadretdinova G.A. (ed.), 1993, Slovar' russkih starožil'českih govorov Srednego Priirtyš' $a$, vol. 2, Tomsk: Izdatel'stvo Tomskogo universiteta.

Sl. cerk.-sl. 1947 - Slovar'cerkovno-slavânskogo i russkogo âzyka, sostavlennyj II otdeleniem Imperatorskoj Akademii nauk, 1847, Sankt-Peterburg, http://etymolog.ruslang.ru/index. php?act=dict1847; 18.10.2019.

SRNG-8 - Filin F.P., Sorokoletov F.P. (eds.), 1972, Slovar' russkih narodnyh govorov, iss. 8, Leningrad: Nauka.

SRNG-21 - Filin F.P., Sorokoletov F.P. (eds.), 1986, Slovar' russkih narodnyh govorov, iss. 21, Leningrad: Nauka.

SRNG-22 - Filin F.P., Sorokoletov F.P. (eds.), 1987, Slovar' russkih narodnyh govorov, iss. 22, Leningrad: Nauka.

SRNG-31 - Sorokoletov F.P., Kuznecova O.D. (eds.), 1997, Slovar' russkih narodnyh govorov, iss. 31, Sankt-Peterburg: Nauka.

SRNG-40 - Sorokoletov F.P., Kuznecova O.D. (eds.), 2006, Slovar' russkih narodnyh govorov, iss. 40, Sankt-Peterburg: Nauka.

SRNG-42 - Sorokoletov F.P., Kuznecova O.D. (eds.), 2006, Slovar' russkih narodnyh govorov, iss. 42, Sankt-Peterburg: Nauka.

TÈS 2006 - Tolkovyj ènciklopedičeskij slovar', 2006, Sankt-Peterburg: Norint.

\section{Литература}

Černyh P.Â., 2002, Istoriko-ètimologičeskij slovar'sovremennogo russkogo âzyka, vol. 1, Moskva: Russkij âzyk.

Dal' V.I., 1989, Tolkovyj slovar'živogo velikorusskogo âzyka, vol. 2, Moskva: Russkij âzyk. Filin F.P. (ed.), 1981, Leksika russkogo literaturnogo âzyka XIX-načala XX veka, Moskva: Nauka.

Grigorovskij N.P., 1870, Krest'âne-starožily Narymskago kraâ, Zapiski Zapadno-Sibirskogo otdela Imperatorskogo geografičeskogo obŝestva, Kniga I, pp. 2-28.

Grot Â.K., 1895, Russkoe pravopisanie. Rukovodstvo, sostavlennoe po poručeniû vtorogo otdeleniâ Imperatorskoj Akademii nauk, Sankt-Peterburg: Tipografiâ Imperatorskoj Akademii nauk.

Harlamova M.A., 2019, Sibirskaâ publicistika XIX veka kak leksikografičeskij istočnik [in:] V.N. Kalinovskaâ, I.A. Malyševa (eds.), Slavânskaâ istoričeskaâ leksikologiâ i leksikografiâ, iss. 2, Sankt-Peterburg: Institut lingvističeskih issledovanij RAN, pp. 265-274.

Kvitka M., 1899a, K' opisaniû gorodov' i selenij. Svâtki u tobol'skih' krest'ân', Dorožnik po Sibiri i aziatskoj Rossii, Kniga V, pp. 45-50.

Kvitka M., 1899b, K' opisaniû gorodov' i selenij II. Krest'ânskaâ svad'ba v' Turinskom' uězdě, Tobol'skoj gubernii, Dorožnik po Sibiri i aziatskoj Rossii, Kniga VI, pp. 22-28.

Meŝerskij N.A. (ed.), 1972, Russkaâ dialektologiâ, Moskva: Vysšaâ škola. 
Ožegov S.I., 1984, Slovar' russkogo âzyka, Moskva: Russkij âzyk.

Rozental' D.Ė., 1994, Spravočnik po orfografii i punktuacii, Čelâbinsk: Ûžno-Uralal'skoe knižnoe izdatel'stvo.

Šerstobitov A., 1899, Put' po hlěborodnym' městam'. Ot' Barnaula do Egor'evska, Dorožnik po Sibiri i aziatskoj Rossii, Kniga V, pp. 14-29.

Švarckopf B.I., 1967, Vnimanie: kavyčki!, Russkaâ reč', 4, pp. 60-64.

Ušakov D.N., 1935, Tolkovyj slovar' russkogo âzyka, vol. 1, Moskva: Sovetskaâ ènciklopediâ. 